\title{
Simulating the Expansion of Large-sized Farms in Rural Netherlands: A Land Exchange Model
}

\author{
Shah Jamal Alam ${ }^{1}$, Martha M. Bakker ${ }^{2}$, Eleni Karali ${ }^{1}$, \\ Jerry van Dijk and Mark D. Rounsevell ${ }^{1}$ \\ ${ }^{1}$ School of Geosciences, University of Edinburgh, Edinburgh, UK \\ \{SJ.Alam, Mark.Rounsevell\}@ed.ac.uk ekarali@staffmail.ed.ac.uk \\ ${ }^{2}$ Chair of Land Use Planning, Wageningen University, Wageningen, the Netherlands \\ Martha.Bakkerewur.nl \\ ${ }^{3}$ Faculty of Geosciences, Utrecht University, Utrecht, the Netherlands \\ J.vanDijk2@uu.nl
}

\begin{abstract}
This paper introduces a data-driven agent-based simulation model of rural land exchange in the Netherlands. The model development process is part of an ongoing research program aiming at understanding the effects of climate change and socioeconomic drivers on agriculture land use and nature conservation. The first model version reported in this paper, is being developed for the Baakse Beek region in the Netherlands and is empirically grounded. The general framework described in this paper will be applied to another case study area in the Netherlands in the second phase of our research program and compare the projected land use patterns in the two case studies region.
\end{abstract}

Keywords: agent-based model, land exchange, spatially explicit, data-driven

\section{Introduction}

Agriculture is one of the most important land uses in Europe [1, 2]. Farming activities utilize about half of the surface of the European Union (EU) and are largely responsible for the past and current landscape patterns in rural areas [3, 4]. The Netherlands comprises an exemplar of a country with a dynamic agricultural sector. Agriculture is the largest land use, covering about $70 \%$ of the country's terrestrial surface [5]. During the last decades, it has experienced rapid and extensive changes including decrease in the total number of farms, dominance of dairy farms, dwindling of the pig and poultry sectors, and rise in the number of owner over tenant farmers [5]. Further changes have resulted from the dynamic interactions between agriculture and other land uses. The proximity of rural areas to urban centers [6] for example, has stimulated urbanization at the expense of farmland. Additionally, the implementation of nature management policies along with the development of recreation areas and woodland has led to annual exemptions of farmland from agricultural activities [7].

The aforementioned processes alone decrease farmland surface by about $0.5 \%$ every year [7]. Unavoidably, land transactions are accompanied by modification of the 
use and/or the management land, provoking changes not only in the landscape structure, but also in the range and flow of ecosystem services that they provide [8-10]. Hence, the importance of land tenure as a driver of land use/management decisions increases [11,12]; along with the need to better understand land exchange processes and their implications.

Land use models can be used as tools to simulate land exchange processes and explore their outcomes under the assumptions of alternative future scenarios. Agentbased models simulating land market have largely focused mostly on urban (e.g., [13$15,19])$ rather than rural areas. Although some of these models are quite sophisticated, they have so far, not been used to explore land use change since they require records on land prices and budgets of potential buyers; details that are not likely to be available on the temporal and spatial scales at which land use change becomes manifest. In order to simulate land use change evolving from land transactions a more rigorous approximation of likely transactions needs to be made.

In this paper, we introduce the first version of the RUral Land EXchange (RULEX) model developed in the context of the Climate Adaptation for Rural arEas (CARE) project. This research program, funded by the Dutch government, is designed to generate knowledge that is necessary for the design and evaluation of adaptation strategies to climate change in rural areas in the Netherlands. The RULEX model simulates the process of parcels' evaluation as conducted by agents that represent individual land managers/farmers and land exchange between them. The purpose for developing the model is to generate future land use maps and the development of farm sizes under different socioeconomic and climate change scenarios. A roadmap describing the development and validation cycles for the model is presented. We present preliminary results concerning the expansion of large-sized farms as well as the reduction in the number of small farms under different simulation settings.

\section{The Baakse Beek case study region}

The Baakse Beek region, shown in Fig.1, is located in the Province of Gelderland, in the eastern part of the Netherlands, defined by the boundaries of a watershed. This is a strategic action area according to the provincial water management plan ${ }^{1}$. The integration of rural development processes related to the nature, agriculture and water management play a key role in climate change adaptation strategy.

The introduction of fertilizers and the Common Agricultural Policy (CAP) ${ }^{2}$ have resulted in significant changes in farmland management, namely the heavy cultivation of farmland and the resulting nutrient surplus. Furthermore, intense land use changes have taken place such as the replacement of mixed (arable and some cattle) farms by either arable farms, dairy farms or pig farms, or their purchase by private companies when farmers were not able to find a successor. The current trend involves the dominance of livestock (usually, pigs and dairy are combined) over arable farms. 'Natura 2000 ' sites are located in proximity to the study area, enhancing the ecological value

http://www.baaksebeek.nl/

2 http://ec.europa.eu/agriculture/index_en.htm 
of the area. Disappearance of semi-natural habitats, desiccation and acidification of wet nature areas, increased sensitivity of flood pulses and flooding are some of the issues that land managers and policy-makers are expected to confront with.

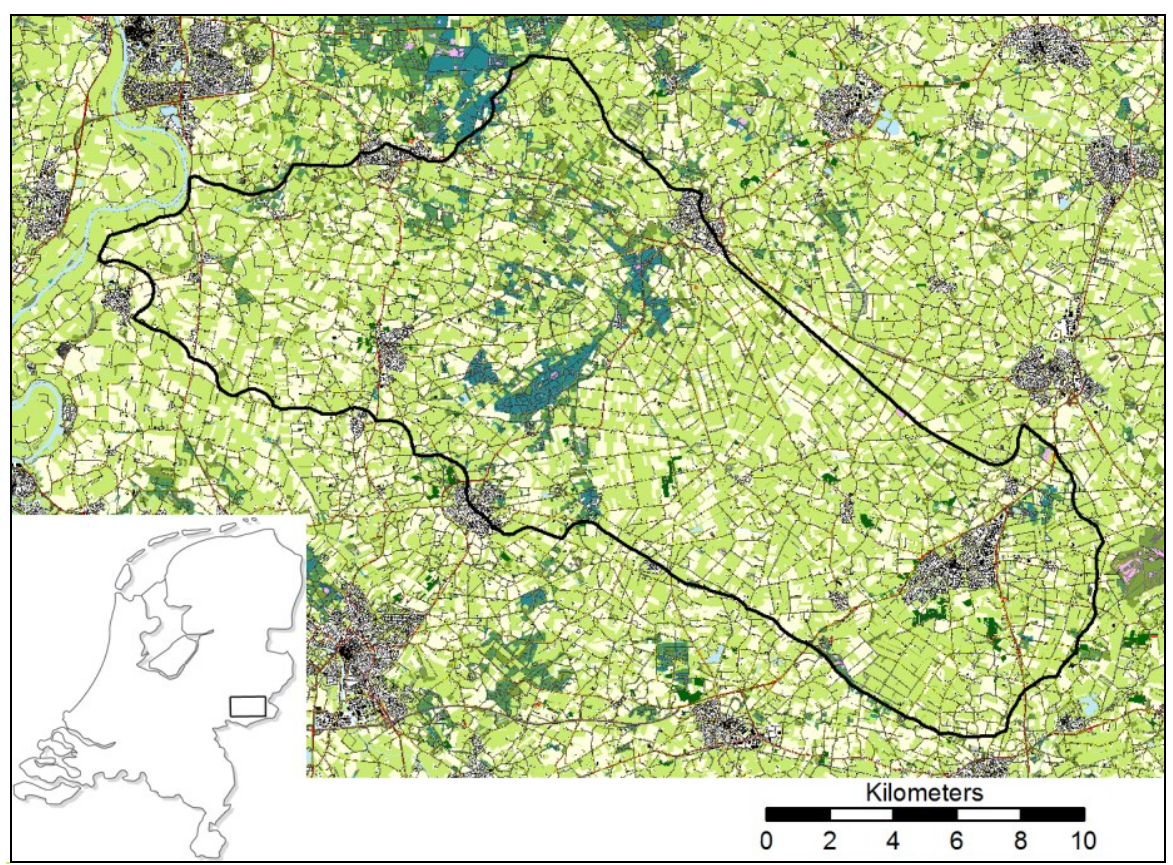

Fig. 1. An map of the Baakse Beek region in the Netherlands (courtesy: Utrecht University)

One of the important issues concerning the Baakse Beek region is an everincreasing size of expanding farms resulting in the loss of small farm elements. Currently, dairy farmers constitute about $70 \%$ of the farmers in Baakse Beek while the rest of the farmers use their land for intensive pigs and poultry, arable, mixed and horticulture. Land parcels with mixed land use tend to be replaced by dairy, arable and pigs/poultry farm. Several other important social and environmental issues exist e.g., whether farmers' would be willing to participate in schemes such as the 'GreenBlue' corridors, or whether the ongoing trend of increasing farm sizes would result in a loss of social cohesion. These issues are addressed elsewhere (in preparation).

\section{$3 \quad$ Materials and methods}

The Rural Land EXchange (RULEX) model incorporates data of different types from different sources following the evidence-driven modeling approach [16, 17]. In RULEX, we have used real land parcel and farm delineations, historical transactions and the available census data. The spatial data of landownership in the Baakse Beek region comes in the form of land parcel ESRI shapefiles and farmers' locations in the region. The agricultural census data from the Gelderland province gives details about 
the farmers' age, land uses, economic size and other demographic information. Shapefiles inform land ownerships, land uses and delineation of the National Ecological Network (NEN). Dairy income loss and soil maps generated from biophysical models that have been developed by our project partners, inform equations that are used to calculate the perceived values of land parcels of the farmer agents.

The RULEX model is developed using Repast Simphony $2.0^{3}$ and uses the Java $\mathrm{JTS}^{4}$ and Geotools ${ }^{5}$ Java libraries. The model runs on an annual time scale. By default, simulation runs for 40 years and the starting year is assumed to be 2009 following the most recent agricultural census data available to us. Next, we present an overview of the model entities, state variables and the simulation schedule.

\subsection{Land use categories}

The basic assumption of the model, consistent with respect to our case study, is that land use change is brought about through land exchange, i.e., a land parcel's current land use depends upon the land use category of its owner. Land use is an input characteristic for farmer agents and an output characteristic for parcels in RULEX. For the first version of the model, we reclassify the existing land use categories (based on the census data) into six broad categories, viz., arable, dairy, pigs-and-poultry, horticulture, mixed and 'nature'. Each farmer agent is assigned exactly one of the above land use categories except 'nature'. The 'nature' land use category concerns with the nature managers (another type of actors) and the National Ecological Network (NEN) policy, which will be incorporated in the next model version.

\subsection{Typification of farmers' strategies for land exchange}

A first step to model exchanges of parcels between farmers is to identify which farmers are likely to buy land, which are likely to sell land, and which are not likely to participate in the land exchange process at all. Using the panel agriculture census data of 1999 and 2009, we classified farmers in the case study region into four types: expanders, shrinkers, intensifiers and stable. Those farmers whose area increased at least $10 \%$ in the past 10 years were identified as expanders; those whose area decreased by more than $10 \%$ were identified as shrinkers. Farmers whose economic size increased during this time were identified as intensifiers while the rest were identified as stable farmers. Farmer agents initialized based on 2009 census data are then initialized strategy probabilistically based on their existing profile that is updated at each time step (see Section 3.4). In our model, we use the Dutch equivalent of the European economic size, called Nederlandse Grootte Eenheid (NGE) ${ }^{6}$.

\footnotetext{
http://repast.sourceforge.net/

$4 \mathrm{http}: / /$ www.vividsolutions.com/jts/JTSHome.htm

$5 \mathrm{http}: / / \mathrm{www}$.geotools.org/

${ }^{6} \mathrm{http}: / /$ epp.eurostat.ec.europa.eu/statistics_explained/index.php/Farm_structure_in_the_Netherl ands
} 


\subsection{Agents representing farmers in Baakse Beek}

Agents in the first version of the model represent existing farmers in the Baakse Beek region. As of 2012, analysis of the land parcels ownership data identified 1259 farmers in Baakse Beek who own at least one land parcel. We use the land parcels delineation and the ownership data to match it with the most recent census data (for the year 2009) of these farmers in the region. In our model, simulation starts with each agent representing the existing owners of the agriculture land parcels in the case study region. Each agent is assigned land parcels ownership, land use category, age and the calculated economic size. Agents are assigned geographical locations in the region: for corresponding resident farmers, for whom a geographical location is available, a position is assigned in the geometry. For farmers whose location is missing, we assume that they live outside and hence a random location is assigned outside the region. Table 1 summarizes the attributes of farmer agents in the model.

In the first version, we assume that no new agents representing land managers enter the system during a simulation run. On the other hand, shrinking farmer agents who have sold away all of their parcels leave the system. Thus, we observe a decrease in the number of farmers; a trend that has been observed in the case study region and informed by the domain experts.

Table 1. Attributes and description of agents representing farmers in the Baakse Beek region; the last column indciates whether an attribute changes during a simulation.

\begin{tabular}{|c|l|c|}
\hline Agent attribute & \multicolumn{1}{|c|}{ Description } & Updated? \\
\hline BRS_ID & A farmer's registration number as in the agriculture census & No \\
\hline Land use type & $\{$ arable, dairy, pigs-and-poultry, horticulture, mixed & No \\
\hline Area in BB & Total area in hectares owned in the Baakse Beek region & Yes \\
\hline Age & Initialized from 2009 census & Yes \\
\hline Economic size & Farmer agent's total economic size (NGE) in Baakse Beek & Yes \\
\hline Strategy & $\{$ Expand, Shrink, Intensify, Remain stable & Yes \\
\hline
\end{tabular}

\subsection{Agents' methods}

Updating attributes. At each time step, a farmer agent is assigned one of the four strategies (see Table 1). The probabilities for the four strategies are calculated from equations that are estimated using multinomial regressions on the agriculture census data for 1999 and 2009. Based on our analysis (in preparation), the factors taken into account were: age, dairy $\{$ Boolean\}, area, economic size and whether the farmer agent had an expanding strategy in the previous time step \{Boolean\}. In our model, a farmer agent's land use type is the only static attribute besides its BRS_ID. At each time step, age is incremented. The total area, in hectares, of a farmer agent changes over time when they buy or sell land parcels as expanding or shrinking agents respectively. While the expanding and shrinking farmer agents buy and sell land parcels respectively, intensifiers augment their NGE each year (default: 1.7 per ha.), whereas 
stable farmer agents currently do nothing in the model (unless they change strategy in subsequent time steps).

Price-prepared-to-pay (PPP) aka perceived-value of a land parcel. Estimating the price that an expanding farmer would be willing to pay is difficult. For the Baakse Beek case study, data is available on sale transactions and the prices paid, however, the actual price paid is not the same as the price that a potential buyer would be willing to pay. In our model, we consider PPP as the value of a piece of land that a land manager, in our case, a farmer agent would perceive or would be willing to pay. In order to estimate that, it is important to know which parcels are more likely to be placed in the market by shrinking farmers and which parcels are more attractive to the potential buyers (in this case, the expanding farmers). We have used regression analysis (to be reported elsewhere) on the land transactions data to estimate parameters of the equation used by farmer agents in our model, in Eq. 1 below.

$$
\begin{gathered}
\mathrm{PPP}_{\text {farmer }}=40670-12.224 * \text { distance }_{\text {parcel }}+5747749 * \text { distance }_{\text {village }}{ }^{-1} \\
-883356.7 * \text { distance }_{\mathrm{NEN}}^{-1}+209.5 \text { incomeloss }_{\text {dairy }}-9760.1
\end{gathered}
$$

Fig. 2 highlights the factors taken into account to estimate farmer agents' perceived value of land parcels. Proximity to a land parcel is the most dominant factor in determining its desirability; we observe a sharp decline in the trend of purchasing parcels that are distant and almost no purchases observed beyond $5 \mathrm{~km}$ distance. Other factors also contribute to a farmer agent's perceived value. For instance, the distance to the National Ecological Network (NEN) - due to the government's NEN policy, a parcel that lies within NEN or is near, has of little desirability to expanding farmers and thus as seen in Eq. 1, a parcel's proximity to NEN decreases its price that a potential buyer (expanding farmer) may be willing to pay. While the factors included in Eq. 1 give a good fit for the land transactions in Baakse Beek, we are currently conducting sensitivity analysis for these estimates on the model's outputs. As Fig. 3 illustrates, determination of farmers' perceived values of land parcels based on the parcels' location and biophysical features, may result in a situation where expansion of existing farms are limited by the lack of desirable land parcels for sale (a sellers' market case); or when shrinking farmers are left with unsold parcels because of a lack of interested buyers in the vicinity (a buyers' market case).

Succession of farms. In Baakse Beek, succession of farms occurs when a farmer dies or retires from farming. In RULEX, a farmer agent retires when a farmer attains a retirement age (default: 67 years) and has an economic size $>8.2$ (estimated). Otherwise, a farmer agent stays until it dies. If a farmer agent retires or dies, we assume that its successor takes over. This we do by resetting the age (age $\leftarrow$ age -35 years). Notice that age is one of the factors that determine an agent's strategy that is updated each year. In our model, agents die based on the probabilities reported in the WHO life expectancy tables for the Netherlands ${ }^{7}$. Model assumptions concerning succession

7 http://apps.who.int/gho/data/view.main.61160?lang=en 
can affect the model's results [18] and we aim to test these assumptions and alternative succession mechanisms in the next RULEX version.

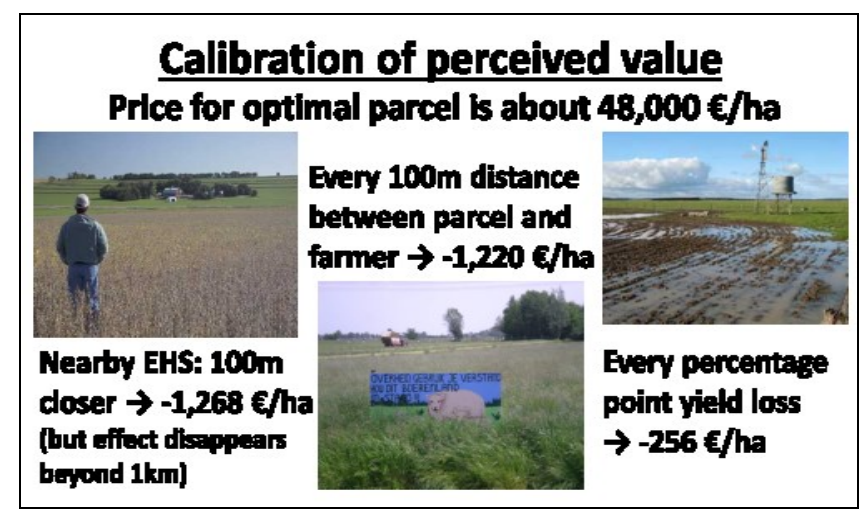

Fig. 2. Calibration of perceived value by farmer agents in the RULEX models taking into account the shortest distances to a given land parcel, the National Ecological Network and the nearest village (also, a possible loss of income due to climate change).

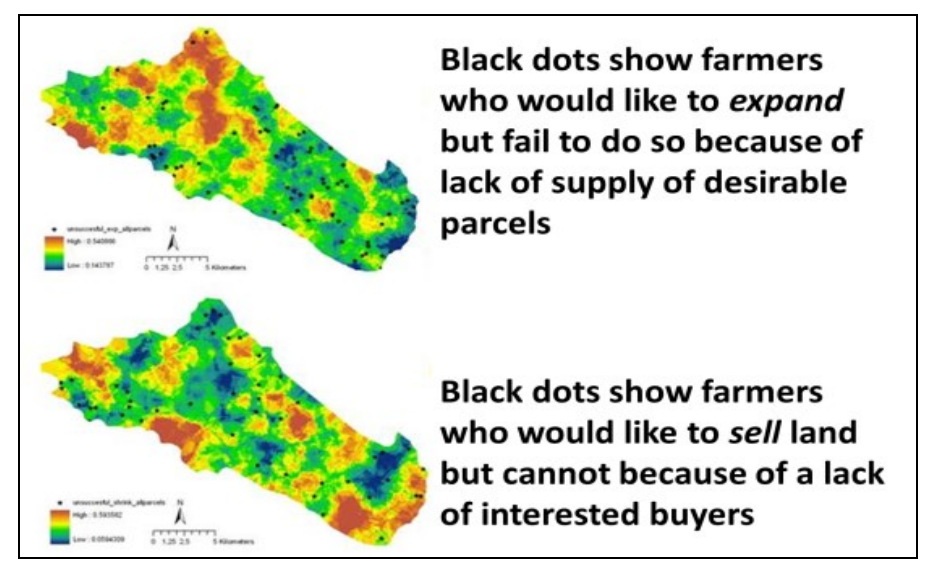

Fig. 3. Right: Two cases depicting sellers' and buyers' market scenarios respectively.

Land exchange. Fig. 4 gives an outline of the simulation schedule at each time step (year) in the model. The model starts with loading the land use map and census data from 2009 and all assigning strategies to all farmer agents (see Table 1) based on the farmer agent's current age, land use type, total area and economic size. Shrinking farmer agents select the least preferred land parcels (the number of parcels put on sale per year is a model parameter; default=1) and put them in the market for sale. In RULEX, when a farmer agent notices that the parcel(s) it had placed in the market did not sell the previous year, i.e., it was not attractive to buyers; it puts his next least preferred parcel for sale and so on. The preferential ranking of parcels is based on a farmer's agents perceived value of a land parcel calculated using Eq. 1. This parame- 
ter can have an effect on the model outputs: If the shrinking farmer agents attempt to sell a lot of parcels then the expanding farmer agents may have a lot more parcels to choose from and thus leading to more land consolidation (as buyers prefer adjacent or nearest parcels). On the other hand, if the shrinking farmer agents sell fewer parcels at or if there are fewer sellers in the system, then the expanding farmer agent may end up buying less favorable land parcels.

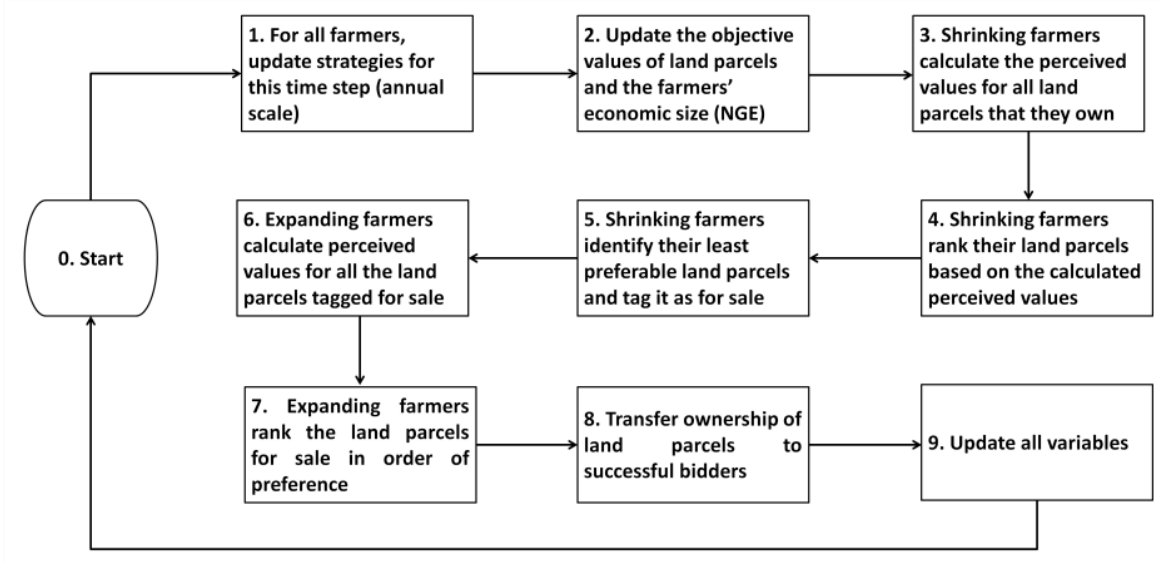

Fig. 4. An outline of the processes in the RULEX model at each time step of a simulation run.

Expanding farmer agents evaluate all land parcels that are available in the market by calculating their perceived values and rank them in the order of preference. An expanding farmer agent bids for only those parcels for which its perceived value is greater than 24,520 (a threshold value; calibrated from data). Here we introduce another model parameter that limits the bidding capacity of a buyer. That is, an expanding farmer agent is allowed to bid for a certain area for sale in a given time step, which is a percentage (default: $30 \%$ ) of the total area of land it currently owns. Since a farmer agent's economic size (NGE) is proportional to the area it owns, the total area owned by a farmer agent is used as a proxy for its purchasing power in the model. If there is more than one bidder for a land parcel, the one with the highest competitive power wins the bid and is transferred ownership of the land parcel. In the current model version, bidders compete based on their economic size (NGE) the bidder with the highest NGE becomes the new owner of the parcel. Notice that the RULEX model simulates land transactions without considering actual monetary values. This allows applying the model over wider spatial and temporal scales in the subsequent phase of the CARE project. Finally, following succession (described above), agents' age, area and NGE are updated. 


\section{$4 \quad$ Preliminary results}

In RULEX, farmer agents receive feedback on their strategies based on the performance, i.e., a change in economic size (NGE) that might be affected by a suite of climate change and socioeconomic scenarios. Since NGE is one of the factors that affect farmer agents' strategies, penalizing an expansion strategy would imply that expander agents would be less likely to expand when their economic performance is low. These scenarios will be explored in the subsequent model version following the model's validation with farmers and other stakeholders as part of the RULEX model's development process. Table 2 gives a list of the model's general and region-specific parameters and their default values. Here, we list only the intercepts of the regression equations that are used to calculate the respective probabilities for the four strategies (see Table 1) of farmer agents. One could simulate the effects of buyers' and sellers' market in the region by exploring different values of these intercepts.

Table 2. RULEX (version 1.0) Baakse Beek region-specific and general parameters

\begin{tabular}{|c|c|}
\hline Region-specific parameters & General parameters \\
\hline Regression coefficients for strategy: & Retirement age (67 years) \\
\hline Expander (intercept) $\quad-2.961348$ & \\
\hline Intensifier (intercept) & Maximum age of farmer (90 years) \\
\hline Shrinker (intercept) & $\begin{array}{l}\text { Age difference between farmer and successor } \\
\text { ( } 35 \text { years) }\end{array}$ \\
\hline $\begin{array}{l}\text { Regression coefficients for price pre- } \\
\text { pared to pay (see Eq. 1) }\end{array}$ & $\begin{array}{l}\text { Maximum number of parcels offered for sale } \\
\text { by shrinkers per year (1) }\end{array}$ \\
\hline NGE threshold for a successor 8.2 & Percentage of total area of which an expander \\
\hline $\begin{array}{l}\text { Annual NGE/ha increase for intensifiers } \\
(1.7)\end{array}$ & is allowed to bid in a year $(30 \%)$ \\
\hline $\begin{array}{l}\text { Threshold for buying land ( } 24520 \text { eu- } \\
\text { ros/ha) }\end{array}$ & \\
\hline
\end{tabular}

We report the model's outputs based on five different parameter settings that are described in Table 3. We select three parameters: the maximum number of parcels that a shrinking farmer agent puts in the market in a year (NumParcels); the percentage of total area of which an expanding agent is allowed to bid in a year (PerExp) and three different values for the shrinking agent's intercept (see Table 2). We run the model for 40 time steps (years) beginning with 2009 as the starting year.

The outputs generated by the model include the time series of the number of farmer agents with respect to their strategies and land use types and the total area covered under different land use categories. Furthermore, we look into the effect of these settings on land consolidation - i.e., assuming that farmer agents who would merge adjacent lands as one patch for more convenient land management. Whether a marketbased land exchange results in further fragmentation or consolidation of land in the case study region is an important policy question for the stakeholders. 
Table 3. Five simulation settings based on different values of the model parameters.

\begin{tabular}{|c|c|c|c|}
\hline Setting & NumParcels & PercExp & ShrinkerIntercept \\
\hline I & 1 & $30 \%$ & -1.473086 \\
\hline II & 2 & $30 \%$ & -1.473086 \\
\hline III & 3 & $30 \%$ & -1.473086 \\
\hline IV & 3 & $10 \%$ & -2.473086 \\
\hline V & 1 & $10 \%$ & -3.473086 \\
\hline
\end{tabular}

Measuring consolidated patches on land parcels in a vector-based geometry can be tricky as the delineation of land parcels in a shapefile format needs to be correct in order to determine neighboring land parcels. In contrast, for grid-based representation of land parcels, identifying consolidated patches is straightforward. Here have used a distance threshold of $20 \mathrm{~m}$ to determine if two land parcels are adjacent or not, and identify them as belonging to a consolidated patch if both belong to the same farmer agent. Several metrics ${ }^{8}$ are reported in the literature for measuring land fragmentation in a study region. Here we use an adaptation of the 'patch density' measure of land consolidation, which is the total area that is owned by a farmer agent divided by the number of land parcel; we report the average patch density as a time series.

Fig. 5 shows the time series for the average patch density and the total number of farmers for the five settings (see Table 3). The model parameter limiting the number of parcels that can be put on sale in a year by a shrinking farmer agent has a significant effect on the rate and extent to which farm size increases in the simulation. The more parcels that are put on sale by shrinking agents, the more choice expander agents have and thus the chances for expanders to bid for parcels that are in proximity increases with time. Notice that the expanding agents only bid for a 'for-sale' parcel if their perceived value exceeds a given threshold (Table 3). For the shrinking agents, this means that they are able to sell off their land parcels more quickly and thus the total number of agents decreases with time. The second model parameter, which limits the bidding capacity of expander agents, also affects the number of total farmer agents that survive in the system after 40 years (time steps). Unfortunately, we do not have the data to calibrate these two model parameters and this therefore requires uncertainty analysis on these parameters (currently in progress).

In the past decade, there has been a $40 \%$ reduction in the number of farmers based on the national-level statistics. As we can see in Fig. 5, different parameter settings lead to an overall reduction ranging from approximately 20 to $70 \%$. Another observable trend in the case study region is the increasing dominance of dairy farmers, which is reflected from the simulation results shown in Fig. 6 and in Fig. 7, which shows two snapshots of land use spatial patterns for 2009 and 2050.

8 See [21, 22] for more land consolidation measures 


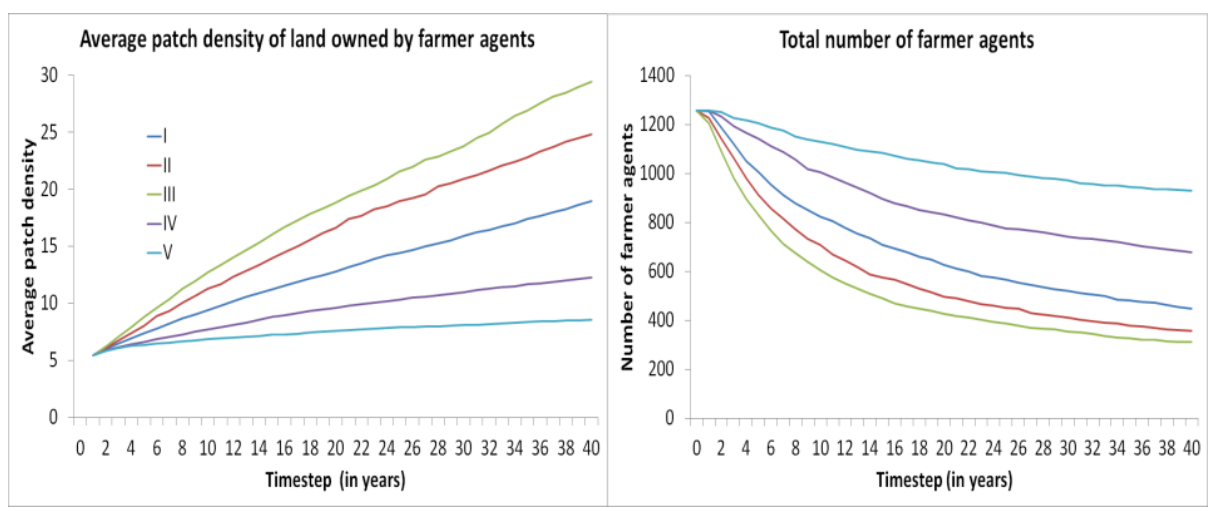

Fig. 5. Left: total area (in hectares) owned by farmer agents. Right: total number of farmer agents in the system.

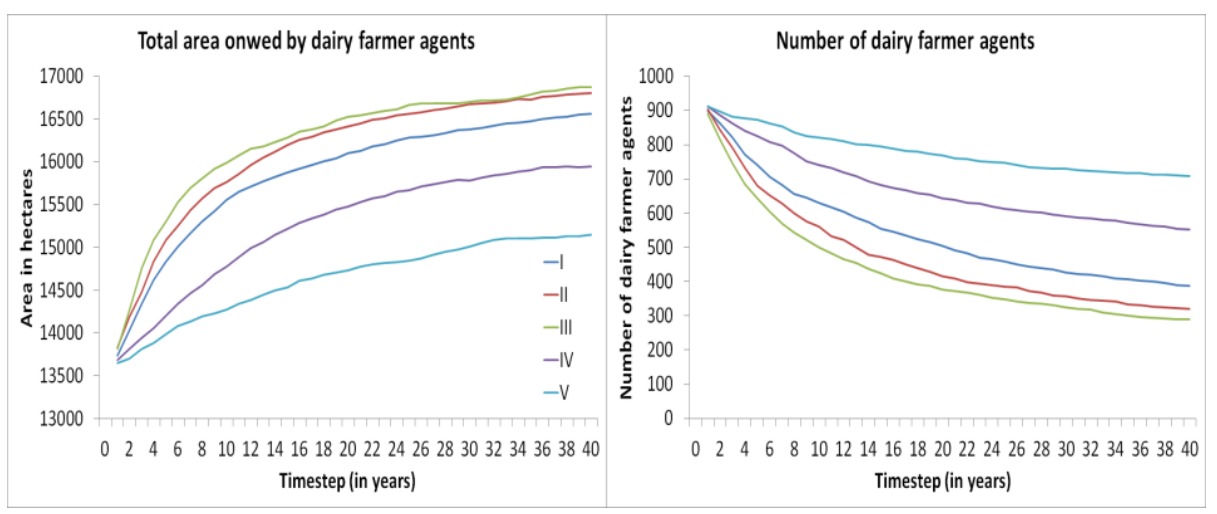

Fig. 6. Left: total area (in hectares) owned by dairy farmer agents. Right: total number of farmer agents in the system. 


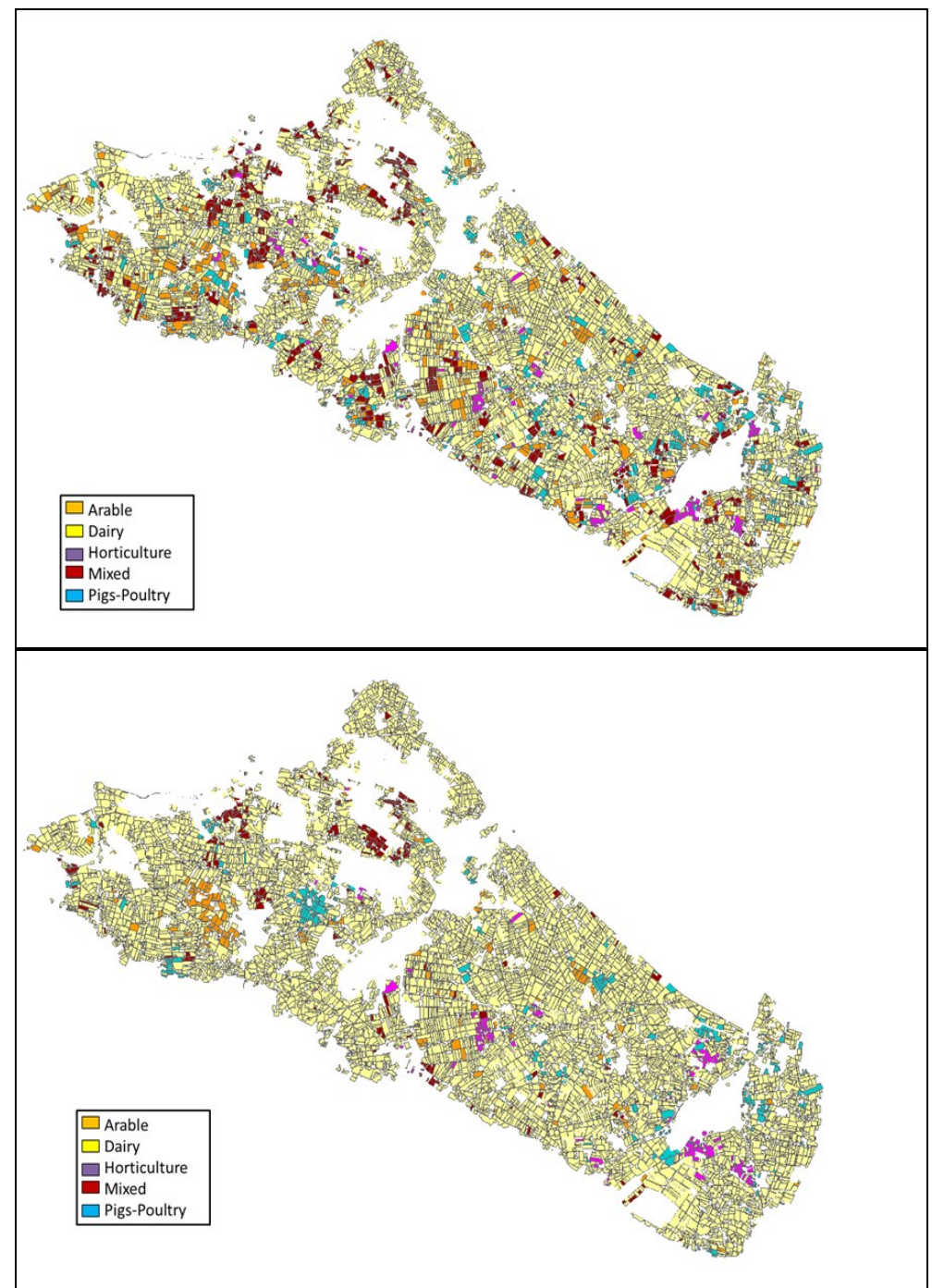

Fig. 7. Above: land use of parcels based on the respective owners in the Baakse Beek region in 2009 (time step: 0). Below: simulated land use of parcels for 2050 (time step: 40).

\section{Outlook}

The RULEX model is currently being developed to study trends in increase of farms size under different climate and socioeconomic scenarios. Land exchange in RULEX incorporates exchange and bidding processes and takes place on a spatially explicit landscape. In this paper, we have reported the first results that were run without a scenario configuration and feedbacks. Our modeling approach has been to find a neutral solution of not optimizing either from the ecological or economic perspectives, 
instead to mimic the observed behavior to engage the farmers in the Baakse Beek region and other stakeholders.

The model will undergo revisions following the feedback from the stakeholders and then we will introduce another type of land managers, i.e., nature manager organizations that are interested in the conservation of nature areas in the region. This will allow a cross-sectorial competition analysis for land resources between the two actor types that have different desirability for a land parcel that is on sale and different land use. Modeling nature managers' behavior (decision-making) is an unexplored subject and will be included in the next phase.

Acknowledgements. This work is supported under the Knowledge for Climate Research Programme in the Netherlands. We are thankful to our partners in the CARE Project consortium for their valuable feedback.

\section{References}

1. Schmit, C.: Analysing spatial patterns and representations of agricultural land use cata. $\mathrm{PhD}$ thesis. Université catholique de Louvain (2006)

2. Verburg, P.H., Schulp, C.J.E., Witte, N., Veldkamp, A.: Downscaling of land use change scenarios to assess the dynamics of European landscapes. Agriculture, Ecosystems and Environment. 114, 39-56 (2006)

3. Schmitzberger, I., Wrbka, T., Steurer, B., Aschenbrenner, G., Peterseil, J., Zechmeister, H.G.: How farming styles influence biodiversity maintenance in Austrian agricultural landscapes. Agriculture, Ecosystems \& Environment. 108, 274-290 (2005)

4. Valbuena, D., Verburg, P.H., Bregt, A.K.: A method to define a typology for agent-based analysis in regional land-use research. Agriculture, Ecosystems \& Environment. 128, $27-$ $36(2008)$

5. UN Report of the Netherlands. Sustainable development in agriculture, land and rural development, drought and desertification and Africa (2008) http://www.un.org/esa/agenda21/natlinfo/countr/nether/

6. OECD Rural Policy Reviews: Netherlands. ISBN: 9789264041967 (2008)

7. LNV-The Netherlands Ministry of Agriculture, Nature and Food Quality. National report on Land use, land registration and land development in the Netherlands (2006) Retrieved from www.icarrd.org/en/icard_doc_down/national_Netherlands.doc

8. Donald, P.F., Sanderson, F.J., Burfield, I.J., van Bommel, F.P.J.: Further evidence of continent-wide impacts of agricultural intensification on European farmland birds, 1990-2000. Agriculture, Ecosystems \& Environment. 116, 189-196 (2006)

9. Sattler, C., U.J. Nagel, U.J.: Factors affecting farmers' acceptance of conservation measures-A case study from north-eastern Germany. Land Use Policy. 27, 70-77 (2010)

10. Murray-Rust, D., Dendoncker, N., Dawson, T.P., Acosta-Michlik, L., Karali, E., Guillem, E., Rounsevell, M.D.: Conceptualising the analysis of socio-ecological systems through ecosystem services and agent-based modelling. Journal of Land Use Science. 6, 83-99 (2011)

11. Evans, T.P., Moran, E.F.: Spatial Integration of Social and Biophysical Factors Related to Landcover Change. Population and Development Review. 28, 165-186 (2002)

12. Land Tenure Studies 3. Land tenure and rural development (2002) Retrieved from ftp://ftp.fao.org/docrep/fao/005/y4307E/y4307E00.pdf 
13. Filatova, T., Parker, D.C., van der Veen, A.: Agent-Based Urban Land Markets: Agent's Pricing Behavior, Land Prices and Urban Land Use Change. Journal of Artificial Societies and Social Simulation. 12, 3 (2009) http://jasss.soc.surrey.ac.uk/12/1/3.html

14. Filatova, T., Voinov, A., van der Veen, A.: Land market mechanisms for preservation of space for coastal ecosystems: An agent-based analysis. Environmental Modelling \& Software. 26, 179-190 (2011)

15. Parker, D.C., Brown, D.G., Filatova, T., Riolo, R., Robinson, D.T., Sun, S.: Do Land Markets Matter? A Modeling Ontology and Experimental Design to Test the Effects of Land Markets for an Agent-based Model of Ex-urban Residential Land-use Change. In: Agent-based Models of Geographical Systems. Springer, pp. 525 - 542 (2012)

16. Alam, S.J., Meyer, R., Ziervogel, G., Moss, S.: The impact of HIV/AIDS in the context of socioeconomic stressors: an evidence-driven approach. Journal of Artificial Societies and Social Simulation. 10, 7 (2010) http://jasss.soc.surrey.ac.uk/10/4/7.html

17. Bakker, M.M., van Doorn, A.M.: Farmer-specific relationships between land use change and landscape factors: Introducing agents in empirical land use modelling. Land Use Policy. 26, 809-817 (2009)

18. Schindler, J.: The importance of being accurate in agent-based models - an illustration with agent aging. In: 10th German Conference on Multiagent System Technologies. LNAI 7598. Springer, pp. 165-177 (2012)

19. Matthews, R.B., Gilbert, N.G., Roach, A., Polhill, J.G., Gotts, N.M.: Agent-based land-use models: a review of applications. Landscape Ecology. 22, 1447-1459 (2007)

20. Irwin, E.G., Bockstael, N.E.: The evolution of urban sprawl: Evidence of spatial heterogeneity and increasing land fragmentation. PNAS. 104, 20672-20677 (2007)

21. Aslan, S.T.A., Gundogdu, K.S., Arici, I: Some Metric Indices for the Assessment of Land Consolidation Projects. Pak. J. of Biol. Sci. 10, 1390-1397 (2007) 